\title{
Citizen Politics in Times of Crisis
}

\author{
Marco Giugni $^{1} \cdot$ Maria T. Grasso ${ }^{2}$
}

Published online: 10 June 2019

(c) Springer Nature Limited 2019

The economic crisis starting in 2008, also known as the Great Recession, has led to rising unemployment and shrinking GDP across Europe. About 10 years since its onset, there is great variation in the economic conditions of different countries in Europe. As citizens still struggle to cope with the effects of the economic crisis, attention has been drawn to the potential social and political effects of the recession. The experience of economic difficulty can certainly be understood to generate grievances which people may seek to redress through political action. Particularly during periods of economic challenges, macroeconomic conditions might fail to meet expectations resulting in feelings of deprivation and dissatisfaction. In this way, economic crises may provide the political space and motivations for the mobilization of various groups. Particularly in those countries worst hit by the crisis, large protests took place as European governments were blamed for the negative economic context. Protest parties have also been able to attract large proportions of electoral support across the continent. Moreover, in several countries the economic crisis was linked in with pre-existing political crisis, broadening critiques to the entire political system and fostering requests for "real democracy now" such as with Spain's Indignados movement.

At a time where the political context is rife with diverse sources of dissatisfaction, it appears particularly important to understand the effect of deprivation and economic evaluations on diverse types of political action and political attitudes such as populism and anti-immigrant sentiment. Exploring these dynamics in a comparative context leads to our special issue's novel contribution. How did deprivation and other political attitudes impact on political behaviours in times of crisis? Despite the central importance of investigating these questions in the current historical juncture, the scholarly literature is fragmented and underdeveloped in key areas. There is

Marco Giugni

marco.giugni@unige.ch

Maria T. Grasso

m.grasso@sheffield.ac.uk

1 Department of Political Science and International Relations, University of Geneva, Boulevard du Pont-d'Arve 40, 1211 Geneva 4, Switzerland

2 Department of Politics, University of Sheffield, Elmfield, Northumberland Road, Sheffield S10 2TU, UK 
very little research on the economic correlates of populist attitudes and the electoral and non-electoral participation literatures tend to talk past each other. The political science literature on the impact of the economy on political activity is narrowly focused with the widely tested theory of economic voting suggesting that individuals reward incumbents when the economy is doing well but punish them when the economy is doing badly. Moreover, although the concept of deprivation has received growing interest, it remains unclear in the literature how it should be best operationalized. As such, the papers in this special issue also aim to contribute to theorizing on how deprivation should be understood in both objective and subjective terms, at the micro and macro level and as a combination of these.

By pushing the frontiers of research in all these respects and combining the insights from different literatures, this special issue will thus provide a state-of-theart comparative and empirical profile of political attitudes and behaviours in times of crisis. The papers will all employ the same dataset from nine European countries (France, Germany, Greece, Italy, Poland, Spain, Sweden, Switzerland, and UK) collected as part of a cross-national survey we fielded in $2015(N=18,370)$ with a questionnaire tailor-made to answer our research questions. This survey was conducted in the context of the collaborative project "Living with Hard Times: How Citizens React to Economic Crises and Their Social and Political Consequences" (LIVEWHAT), funded by the European Commission under the auspices of the 7th Framework Programme (Grant Agreement Number 613237). First drafts of the papers were presented at a research project workshop at the Scuola Normale Superiore, Florence, in December 2015. Each paper then entered first an internal reviewing process and then an external one following standard practice.

Each of the six papers that form this special issue speak to the general theme outlined above, examining how the Great Recession has-directly or indirectlyaffected citizens' political attitudes and behaviours. Marco Giugni and Maria Grasso focus on the role of blame assignment and show that individuals who blamed the national government for the economic crisis and who were more unsatisfied with the government's handling of unemployment were more likely to take part in different political activities, including voting, and that the effect of these variables vary depending on the specific form of participation. Their study suggest that the effect of the perceptions of one's own economic situation on political behaviour is conditional upon the perceptions people have of the way in which the government is dealing with the situation.

Eva Anduiza and Guillem Rico investigate the extent to which economic recession affects citizens' adoption of populist attitudes. In this regard, they look at three aspects that are expected to foster the development of populist attitudes: vulnerability, grievances or personal experience with the crisis, and perceptions of the national economic situation. While they find evidence for all three aspects, their analysis suggests that the main predictor for populist attitudes is not the vulnerability or the economic hardship suffered by the people, but rather the perceptions that citizens have about the economic situation. Therefore, most of the impact of economic hardship on populist attitudes is driven by subjective perceptions of national conditions.

Maria Grasso, Barbara Yoxon, Sotirios Karampampas and Luke Temple similarly examine action repertoires, addressing the relationship between relative deprivation, 
inequalities and different types of social and political action. They show that feelings of relative deprivation and resources have divergent effects on conventional and unconventional participation. Furthermore, they stress the role of the context in this process, showing that, while individual level feelings of relative deprivation have mobilizing effects for protests, this effect is amplified in wider negative economic contexts. Their analysis therefore points to the importance of studying the interaction between micro-level deprivation and inequalities with macro-level contexts for understanding the dynamics of political participation.

Camilo Cristancho, Katrin Uba and Lorenzo Zamponi looks at citizens' attitudes towards political protest. They study more specifically who approves anti-austerity protests, how bystanders' attitudes differ from the activists' approval of protests, how the repertoires of protest relate to the approval of austerity protests, and how these variations relate to country's experience of economic crisis. They show that the experience of protest as well as the severity of the economic crisis both relate to approval of anti-austerity protests, but also that there are differences depending on the type of grievances and which forms of austerity protests are considered, in particular depending on their degree of disruptiveness.

Maria Theiss, Anna Kurowska and Janina Petelczyc, finally, examine how the fact of being denied or granted social benefits or services influence the propensity to protest. They find that both being denied and being granted social benefits or services positively affect the propensity to protest, but that the experience of receiving benefits moderates the impact of being denied among those living in poverty. This speaks to the role of an often neglected factor in the study of political participation, namely the welfare state, therefore, establishing a connection between the social and political spheres.

Barbara Yoxon, Steven Van Huawaert and Johannes Kiess examine a close aspect, namely how individual perceptions of deprivation relate to various forms of anti-immigrant prejudice. They distinguish between objective and subjective relative deprivation, showing that both subjective deprivation and authoritarianism have a significant impact on anti-immigrant sentiments, while objective deprivation does not. They also find that authoritarian submission moderates the effect of relative deprivation on economic forms of anti-immigrant prejudice. More generally, their findings point to the need to bring individual-level predictors back into the study of prejudice. 